\title{
The Kan Extension Seminar: An Experimental Online Graduate Reading Course
}

Emily Riehl

Daniel Kan (1927-2013) has left an indelible mark on algebraic topology and category theory, with highlights including his discovery of adjoint functors and his work developing simplicial homotopy theory. A lesser-known aspect of his lasting influence, however, is pedagogical: in the 1960s he inaugurated what is now known as the Kan seminar, which continues at MIT and has expanded elsewhere. Kan's seminar is a graduate reading course in algebraic topology designed to acquaint students rapidly with the literature. The format is as follows: over the course of a semester, each student is asked to give a few one-hour lectures summarizing classic papers in the field and to engage with the other assigned papers by writing reading responses. Each lecture is preceded by a practice talk of unbounded length conducted in private (i.e., in the absence of the lead instructor) and-importantly-before the reading responses are due. This format aims to teach students how to read papers quickly and at various levels of depth while giving them a chance to refine presentation skills. The seminar has an additional social element: Kan traditionally hosted a Halloween party where his students could mingle with members of the Boston algebraic topology community.

Regretting having never had the opportunity to participate myself, I decided to adapt Kan's model for graduate students in category theory. As is the case for many specialized subdisciplines, students

Emily Riehl is a Benjamin Peirce Fellow in the Department of Mathematics at Harvard University. Her email address is erieh1@math . harvard. edu.

Members of the Editorial Board for Doceamus are: David Bressoud, Roger Howe, Karen King, William McCallum, and Mark Saul.

DOI: http://dx.doi.org/10.1090/noti1187 interested in category theory are geographically dispersed without critical mass in any one research center. I therefore decided to move the seminar online, and the "Kan Extension Seminar" was born. ${ }^{1}$

In October 2013 I announced the seminar on The n-Category Café, a blog devoted to higher category theory and related topics of which I am a cohost. From a surplus of applications, I selected twelve students (three based in the US, eight from Western Europe, and one from Australia). ${ }^{2}$ Together we read one paper every two weeks from January to June 2014. The papers I selected range over fifty years: I aimed to balance commonly acknowledged classics in the field with more recent papers that exposed students to a broad range of active research areas.

Each student presented one paper via a private class video chat. Over the course of the following week, that student drafted a blog post for The $n$-Category Café. The other students wrote reading responses in a shared LTEX file and were expected to comment on the blog. At the seminar's conclusion, eight of the students convened in person to give a series of expository talks as a satellite to the 2014 International Conference in Category Theory in Cambridge, England.

A video chat is not the most obvious way to discuss mathematical ideas. Our software was simple-each participant appeared in a little box on the computer screen. More elaborate videoconference technology exists, but I did not want to assume all of my students had access to the necessary equipment. A few students prepared

\footnotetext{
${ }^{1}$ The title of one section in Saunders Mac Lane's Categories for the Working Mathematician asserts that "All Concepts Are Kan Extensions."

${ }^{2}$ The daylight savings time change in April significantly complicated the scheduling of class meetings.
} 
LTEX files that were distributed before their presentations, but most often we simply talked to one another. A side benefit of this format is that students can practice mathematical conversation without the aid of a chalkboard. Think of this as a technologically enabled complement to a skill I've romanticized after reading accounts of mathematical collaborators thinking together while taking long walks outdoors.

The Kan extension seminar functioned almost entirely online, yet despite any superficial similarities, it decidedly was not akin to a MOOC (Massive Open Online Course). Namely, part of the value of the experience was its intimacy, with each student taking a turn to present a paper and the entire class working in close collaboration. I see my students as colleagues with whom I look forward to interacting in the future.

As teaching tends to be, the experience was both more rewarding and more consuming than I had predicted. The rewards came from getting to know the students, watching them excel in their presentations, and seeing them improve in their exposition over the course of the editing process. There was also an unexpected social pleasure: I was able to meet all twelve in person over the six-month period. Our class discussions were lively and provocative. I had chosen papers that personally interested me, several of which I had never read carefully. (I had been advised that the Kan seminar was traditionally hands-off, more peer teaching than instructor driven.) Yet as students enthusiastically wrote lengthy, thoughtful reading responses, I felt impelled to give each response the consideration it deserved.

Based on an exit survey and informal conversations with class participants, the seminar was wildly successful. The reading responses spontaneously transformed into an active dialogue as students responded to one another's work. Two participants even commuted regularly to meet in person to discuss the papers.

The greater category theory community also responded positively. One colleague reported that the seminar "brought new life" to The n-Category Café that hosted us. A large audience, including senior colleagues, attended the satellite talks in June. Students and faculty have expressed enthusiasm for future iterations of the seminar; indeed, I've already been contacted by several prospective students.

An online seminar introduces certain issues beyond those of a typical graduate seminar. For example, I had to negotiate which aspects of the course to make public or keep private. The students' expository blog entries constitute a new resource that will benefit anyone who searches online for one of the published papers.
Nonetheless, the most problematic aspects of the course were the discussions on The n-Category Café (I say this not to detract at all from the content of those conversations). Most of the students were legitimately hesitant about posting comments early in their careers that will remain publicly viewable in perpetuity and leave a digital trail. Yet the larger categorical community clamored for greater access to course content: over the semester, multiple colleagues asked to observe our private discussions, as well as have video chats and the satellite conference uploaded to the Internet. I resisted these overtures in order to shelter the class from a surfeit of observers. Still, one could imagine adopting a different strategy that would benefit the wider mathematical community.

For the pilot version of the Kan Extension Seminar, I selected the best-prepared students from the applicant pool, most of whom were attached to a department active in category theory. The students' advanced backgrounds prepared them for the challenging reading assignments, and when confusion struck, many also had local experts to consult. This choice did, however, privilege those at established centers of category theory (principally abroad), leading to an unfortunate paradox: an online seminar which could reach students anywhere limited itself to participants from specific locales.

An online seminar has the potential to catalyze specialized conversations and collaboration among geographically dispersed mathematicians. A more inclusive approach than the one I took might encourage participants whose research interests diverge from the areas of expertise of their graduate departments. This would provide a welcome antidote to the social forces that accrue benefits to those on the "inside track."

A few other axes for variation: a future seminar could focus on a wider or narrower range of papers, read fewer papers (or include fewer students), or could be targeted differently to a more or less advanced level. Some students were critical of the low-tech software (dreams of peripatetic mathematical conversations aside). As tablets and digital meeting tools become more ubiquitous, it may be easier to host online "chalkboard" lectures.

Dan Kan once told me that if you shake something and it rattles, then there is something inside worthy of further contemplation-a particularly categorical viewpoint. I don't submit that the first iteration of the Kan Extension Seminar proceeded in frictionless silence. Indeed, I do think, following Kan, that that fact suggests it is worthy of further experimentation. 